\title{
Effect of Device Design and Formulation on the In Vitro Comparability for Multi-Unit Dose Dry Powder Inhalers
}

\author{
Jagdeep Shur, ${ }^{1}$ Bhawana Saluja, ${ }^{2,4}$ Sau Lee, ${ }^{3}$ James Tibbatts, ${ }^{1}$ and Robert Price ${ }^{1}$
}

Received 9 January 2015; accepted 20 April 2015; published online 9 May 2015

\begin{abstract}
The focus of this investigation was to understand the design space to achieve comparable in vitro performance of two multi-unit dose dry powder inhalers (DPIs) -Flixotide ${ }^{\circledR}$ Accuhaler ${ }^{\circledR}$ (reference product) and MultiHaler ${ }^{\circledR}$ (test product). Flow field, pressure drop and particle trajectories within the test and reference DPI devices were modelled via computational fluid dynamics (CFD). Micronized fluticasone propionate (FP) was characterized to determine particle size distribution (PSD), specific surface area (SSA) and surface interfacial properties using cohesive-adhesive balance (CAB). CFD simulations suggested that the pressure drop and airflow velocity in the MultiHaler@ were greater than Accuhaler ${ }^{\circledR}$. Two modified test devices (MOD MH 1 and MOD MH 2) were manufactured with the introduction of by-pass channels in the airflow path, which achieved comparable specific resistance and airflow path between the test and reference devices. Assessment of reference product formulation in modified test devices suggested that MOD MH 2 achieved comparable in vitro performance to the reference product. $\mathrm{CAB}$ analysis suggested that adhesion of all FP batches to lactose was different, with batch D showing greatest and batch A least adhesion to lactose. Test DPI formulations were manufactured using four different batches of FP with milled or sieved lactose, and showed that batch A FP formulated with sieved lactose in MOD MH 2 device demonstrated the highest degree of similarity to the Accuhaler ${ }^{\circledR}$ in vitro deposition. Application of CFD modelling and material characterization of formulation raw materials enabled the modification of device and formulation critical material attributes to create an in vitro comparable device/formulation system to the reference product.
\end{abstract}

KEY WORDS: aerosolization; computational fluid dynamics; device design; dry powder inhaler; in vitro comparability; in vitro performance.

\section{INTRODUCTION}

Use of dry powder inhalers (DPIs) for the treatment of chronic respiratory disease has increased considerably in recent years (1). DPI devices generally fall into three categories, single-unit dose devices, multi-dose reservoir

The opinions expressed in this paper by the authors do not necessarily reflect the views or policies of the Food and Drug Administration (FDA).

Electronic supplementary material The online version of this article (doi:10.1208/s12248-015-9775-z) contains supplementary material, which is available to authorized users.

${ }^{1}$ Pharmaceutical Surface Science Research Group, Department of Pharmacy and Pharmacology, University of Bath, Claverton Down, Bath, BA2 7AY, UK.

${ }^{2}$ Office of Generic Drugs, Center for Drug Evaluation and Research, Food and Drug Administration, 10903 New Hampshire Avenue, Silver Spring, Maryland 20993-0002, USA.

${ }^{3}$ Office of Pharmaceutical Quality, Center for Drug Evaluation and Research, Food and Drug Administration, 10903 New Hampshire Avenue, Silver Spring, Maryland 20993-0002, USA.

${ }^{4}$ To whom correspondence should be addressed. (e-mail: bhawana.saluja@fda.hhs.gov) devices and multiple-unit dose devices (1). Diskus ${ }^{\circledR}$ or Accuhaler ${ }^{\circledR}$ is the leading multi-unit dose DPI device on the US market. This DPI device utilizes individually sealed blisters containing one or two micronized active pharmaceutical ingredients (APIs) (e.g. fluticasone propionate in Flovent ${ }^{\circledR} /$ Flixotide ${ }^{\circledR}$ or in combination with salmeterol xinafoate in Advair ${ }^{\circledR} /$ Seretide $\left.\AA\right)$ blended with larger lactose carrier particles. The key barrier for developing a generic or follow-on version of these DPI products is to overcome the complexity associated with DPI device and formulation design, in order to achieve bioequivalence (BE) to the reference (innovator) product. The complex relationship between design of the passive DPI device and physicochemical properties of the powder formulation controls the fluidization, de-aggregation and aerodynamic particle size distribution (APSD) of the emitted dose (ED) (2). This in turn influences regional deposition of drug particles in the lung and, thus, the efficacy and safety of the DPI product (3). Hence, in order to produce a test DPI that closely matches in vitro performance of the reference DPI, it is important to identify the key attributes of the test and reference device and formulation, as well as understand their impact on aerosolization performance. 
It is generally believed that significant differences in specific resistance of the test and reference DPIs may lead to significant differences in pulmonary drug delivery $(4,5)$. The internal force required for fluidization and de-aggregation depends on resistance of the DPI device and patient's inspiratory effort $(6,7)$. For the purpose of increasing the likelihood of establishing in vitro comparability, the specific resistance of a test DPI device should be comparable to that of the reference DPI device. Furthermore, a recent study has shown that variation in the fluid dynamics of an entrained airflow within capsule-based DPIs with similar specific resistance affected powder dispersion and APSD (8). This study highlighted the importance of understanding the complex nature of flow field in the test and reference DPI devices in achieving comparable in vitro performance. Hence, as an initial step towards achieving in vitro comparability of test and reference DPI products, it is important to first design a test DPI device that not only has comparable pressure drop across a range of flow rates, but in which the aerosolization performance of the test DPI device also closely matches that of the reference DPI device.

The complex nature of interfacial interactions between the API and carrier particles governs the overall relationship between the DPI device and the de-aggregation efficiency of the powder formulation, thereby influencing the aerosolization performance of the DPI product (9). Particle size, particle morphology, surface roughness and interfacial chemistry of the API and carrier particles have been shown to play a key role in determining these interfacial interactions (9-14). Whilst the surface and interfacial properties of the API are known to be critical in controlling product performance of DPI products, the primary property characterized for the API component of DPI formulations remains to be the particle size. Thus, for product development, the surface and interfacial properties of the API should warrant a greater degree of characterization in order to ensure consistent performance of a DPI product. For instance, the cohesive-adhesive balance (CAB) approach, determined via colloid probe measurements using atomic force microscopy (AFM), has provided the ability to understand and optimize the characteristics of carrier-based DPI formulations through quantification of the balance of inter-particulate forces of the API within DPI systems $(13,15-17)$. This information on the API is key to achieving in vitro comparability of test and reference DPI products.

The intention of the authors in this investigation was to present a rational approach to achieve comparable performance of two multi-unit dose DPI products based on fundamental understanding of the effect of device design and formulation attributes on the aerosolization performance of DPI products. The DPI devices investigated included Flixotide ${ }^{\circledR}$ Accuhaler ${ }^{\circledR}$ (GlaxoSmithKline, Ware, UK) and MultiHaler® (Cipla, Mumbai, India), which were selected as the model reference DPI device and test DPI device, respectively. The study consisted of two parts as described below.

The first part of the study examined the effect of device modifications on DPI aerosolization performance of the test DPI device. Two modified test devices (MOD MH 1 and MOD MH 2) were manufactured based on the MultiHaler ${ }^{\circledR}$ platform with knowledge gained from the computational fluid dynamics (CFD) simulations of both the Accuhaler ${ }^{\circledR}$ and MultiHaler ${ }^{\circledR}$ devices. These modifications were made in an attempt to achieve comparable specific resistance and flow characteristics between the test and reference DPI devices. In order to isolate the influence of the device on aerosolization performance from that of the formulation, the reference product formulation was used to compare the in vitro performance of the test and reference DPI devices and assess the effect of device modifications on their in vitro comparability.

The second part of the study focused on evaluating the effect of formulation design on in vitro performance of MOD MH 2; selected based on results from the first part of the study that showed MOD MH 2 had better in vitro comparability to the reference device. Several test formulations were prepared to investigate the effect of particle size and surface properties of the API and carrier lactose as well as cohesive and adhesive properties of the DPI formulation on the in vitro comparability of the test and reference DPIs. Based on the paper by Lee et al., the flow rates of 30, 60 and $90 \mathrm{~L} /$ min were selected for CFD and in vitro comparisons of the test and reference DPIs (18).

\section{MATERIALS AND METHODS}

\section{Materials}

Flixotide ${ }^{\circledR}$ Accuhaler ${ }^{\circledR} 100$ (GlaxoSmithKline, Ware, UK, Lot No. 75878, Expiry; June 2010), containing $100 \mu \mathrm{g}$ of fluticasone propionate (FP), with a total fill weight of $12.5 \mathrm{mg}$ (including lactose) in each of the 60 blisters, was chosen as a reference DPI product for the study. Commercial samples of this DPI product were supplied by AAH Pharmaceuticals Ltd. (Coventry, UK) and were within the expiry at the time of testing. In addition, a commercial sample of MultiHaler ${ }^{\circledR}$ was supplied by Lamda Pharmacy (Phagwara, India, Lot No. 086790, Expiry; April 2010). MOD MH 1 and MOD MH 2 (modified MultiHaler® rigs) were prepared by stereolithography and manufactured by Concept Flow Ltd. (Coton, UK).

Micronized FP was supplied by four different vendors, which included batch A (Chemagis Ltd, Bnei Brak, Israel), batch B (Farmabios, Milan, Italy), batch C (Cipla Ltd, Mumbai, India) and batch D (Sterling s.r.l, Perugia, Italy). Sieved (SV003) and milled (ML001) lactose monohydrate was supplied by DFE Pharma (Veghel, Netherlands). In addition, all solvents used were of high-performance liquid chromatography (HPLC) grade (Fisher Chemicals, Loughborough, UK). Ultrapure water was produced by reverse osmosis (Milli-Q, Millipore, Molsheim, France). Analytical quantification of FP was carried out using US Pharmacopeia (USP) reference standard material procured from LGC Standards (Teddington, London, UK).

\section{Computational Fluid Dynamics}

CFD analysis (ANSYS Fluent 6.3) was utilized to evaluate the flow field, pressure drop and particle trajectories within the different DPI devices at flow rates of 30,60 and $90 \mathrm{~L} / \mathrm{min}$ as described by Shur et al. (8). The geometries of the 
Accuhaler ${ }^{\circledR}$ and MultiHaler ${ }^{\circledR}$ were constructed from detailed measurements taken from the marketed devices using a micrometer. Modifications were made to the MultiHaler ${ }^{\circledR}$ to produce MOD MH 1 and MOD MH 2. The flow field generated in each device was then calculated by solving the Reynolds Averaged Navier-Stokes equations together with the realizable k- $\varepsilon$ (19) turbulence model with standard wall functions (20). This enabled the determination of the pressure and airflow velocity distribution in the different airflow paths. Lagrangian particle tracks for 1500 particles (size-30 $\mu \mathrm{m}$ ) were calculated using Fluent Discrete Phase Model (21).

These $30-\mu \mathrm{m}$ particles were chosen for particle tracking simulations since they represent the fines mass fraction generated within inhaler airflow paths as suggested by Stevens et al. (22). Monodispersed particles were used to allow simple comparison between the different device designs. The qualitative conclusions drawn from the study were independent of the chosen particle size $(20-80 \mu \mathrm{m})$.

\section{Airflow Resistance}

The pressure drop of all devices was tested using a method described previously (8). The pressure drop testing system included a Dose Uniformity Sampling Apparatus (DUSA, Copley Scientific, Nottingham UK), Copley critical flow controller TPK (Copley Scientific, Nottingham UK) and a vacuum pump (GE Motors, MI, USA). For this assembly, the DUSA with a mouthpiece adapter was connected to the TPK, a flow meter (DFM 2000, Copley Scientific, Nottingham, UK) and a vacuum source. The pressure measurement port on the DUSA was connected to the flow meter to allow measurement of the device pressure drop at a defined flow rate. The pressure drop was determined at flow rates ranging from 10 to $90 \mathrm{~L} / \mathrm{min}$.

\section{Scanning Electron Microscopy}

The particle morphology of lactose monohydrate materials was investigated using a scanning electron microscope (JEOL 6310, Jeol, Tokyo, Japan) at $15 \mathrm{keV}$. Samples were mounted on carbon sticky tabs (Agar Scientific, Stansted, Essex, UK) and coated with gold to a thickness of $20 \mathrm{~nm}$ prior to imaging (Edwards Sputter Coater, Crawley, UK). Imaging was performed at a magnification of $\times 7000$, in order to view several particles in the same field of view at a high resolution.

\section{Particle Size Distribution and Surface Area Analysis}

Particle size distribution of the materials utilized in this study was performed using a method described previously (8). FP samples were measured by wet-sizing using a Sympatec HELOS and CUVETTE laser diffraction system (Sympatec GmbH, Clausthal-Zellerfeld, Germany) with an R3 lens $(0.9-175 \mu \mathrm{m})$.

Approximately $10 \mathrm{mg}$ of powder was suspended in $5 \mathrm{~mL}$ of HPLC-grade cyclohexane containing 0.5\% lecithin (Acros Organics, Geel, Belgium), which was produced using sonication for $5 \mathrm{~min}$ at $25^{\circ} \mathrm{C}$ and immediately transferred into a $50-\mathrm{mL}$ cuvette to produce an appropriate optical concentration (10-25\%). Similarly, particle size analysis of carrier lactose samples and Flixotide ${ }^{\circledR}$ formulations was carried out in the dry state using the same laser diffraction system with a R4 lens $(0.5-350 \mu \mathrm{m})$ and the RODOS (Sympatec $\mathrm{GmbH}$, Clausthal-Zellerfeld, Germany) dry disperser preset at 2.0 bar. Each measurement was performed in triplicate, and particle size analysis was performed using WINDOX 5.0 software (Sympatec GmbH, ClausthalZellerfeld, Germany).

The specific surface areas of the micronized FP samples were measured using a Gemini 2360 surface area analyzer (Micromeritics Instrument Corporation, Norcross, USA). A five-point Brunauer-Emmett-Teller (BET) nitrogen adsorption analysis was carried out in triplicate after degassing the samples for $24 \mathrm{~h}$ in a FlowPrep 060 degasser (Micromeritics Instrument Corporation, Norcross, USA) (15).

\section{Cohesive-Adhesive Balances by Atomic Force Microscopy}

Quantitative CAB analysis of micronized FP samples was performed using a method described by Begat et al. (15) and Kubavat et al. (23). In order to perform the CAB analysis of the different batches of FP samples, smooth single crystal surfaces of FP and lactose monohydrate were prepared using solvent/anti-solvent crystallization. In this approach, saturated solutions of FP in $2 \mathrm{~mL}$ of acetone were prepared and sonicated prior to filtration via a $0.22-\mu \mathrm{m}$ PTFE membrane filter (Whatman Inc., Clifton, NJ, USA). FP was crystallized using water as the anti-solvent and presented a needle-like morphology exposing the dominant $\{010\}$ face. Lactose was crystallized by introducing saturated droplets between two glass cover slips. Resulting crystals of lactose were then isolated upon cleaving the glass cover slips apart, and the glass cover slip was attached to a magnetic AFM stub.

Prior to AFM force measurements, individual particles from each batch of micronized FP were attached onto standard V-shaped tipless cantilevers with pre-defined spring constants (DNP-020, DI, CA, USA) using an epoxy resin glue (Araldite, Cambridge, UK), as previously described (9). Five probes were prepared for each batch of FP, and all probes were examined with an optical microscope (magnification of $\times 50$ ) to ensure integrity of the attached particle, before allowing the thin layer of glue to dry.

All force measurements were performed with a Multimode AFM and Nanoscope IIIa controller using a Jtype scanner (all Veeco, Cambridge, UK). The AFM was enclosed in a custom-built environmental chamber, in which the ambient conditions were maintained at a constant temperature of $25^{\circ} \mathrm{C}\left( \pm 1.5^{\circ} \mathrm{C}\right)$ and relative humidity of $35 \%$ RH $( \pm 3 \%)$. Individual force curves $(n=1024)$ were conducted over a $10 \mu \mathrm{m} \times 10 \mu \mathrm{m}$ area of each substrate at a scan rate of $4 \mathrm{~Hz}$ and a compressive load of $40 \mathrm{nN}$. A custom-built software was used to extract data contained within each force-volume dataset. These data were analyzed to ensure normal distribution, indicating a uniform contact area between the drug probe and the smooth substrate surfaces. Arithmetic mean and standard deviation were obtained from the cohesive (drug-drug) and adhesive (drug-lactose) force data. The cohesive force data for each individual AFM drug probe was plotted against its respective adhesive force data. This approach enabled the construction of CAB plots for the cohesive-adhesive interactions of the different batches of FP. 


\section{Preparation of Powder Formulations}

Eight test formulations were manufactured using micronized FP batches A, B, C and D with SV003 and ML001. The target-loaded dose for all formulations was $100 \mu \mathrm{g}$ of FP per $12.5 \mathrm{mg}$ of formulation, which was equivalent to $0.8 \%$ $w / w$. Batch sizes for all formulations was $25 \mathrm{~g}$. The blending protocol began with sieving of the coarse lactose monohydrate and API samples through a $250-\mu \mathrm{m}-\mathrm{mesh}$ sieve (Glen Mills Inc., Clifton, NJ, USA). Initially, onethird of the total mass of lactose monohydrate was charged into a 50-mL stainless steel vessel, followed by another layering of the whole amount of API. Another one-third of the total mass of lactose monohydrate was then added to the vessel, which sandwiched the API between two layers of lactose monohydrate. This druglactose monohydrate pre-mix was blended for $15 \mathrm{~min}$ at 22 rpm using a Turbula (Type T2F, Bachofen AG, Basel). Following this, the final third mass of lactose monohydrate was added to the vessel and the blend was mixed for another $15 \mathrm{~min}$ at $22 \mathrm{rpm}$ using the Turbula. These multiple blending steps were used to maximize the blend uniformity. The final blend was passed through a $250-\mu \mathrm{m}-$ mesh sieve to aerate the blend. All blends were stored in tightly sealed polyethylene bags, which were stored at $44 \% \mathrm{RH}, 20 \pm 2^{\circ} \mathrm{C}$.

\section{Filling of Powder Formulations into Test MultiHaler ${ }^{\circledR}$ Devices}

All manufactured formulations were filled into cavities representing the cartridge arrangements of the MultiHaler®, using OmniDose ${ }^{\circledR}$ TT laboratory scale drum filler (Harro Höfliger Verpackungsmaschinen GmbH, Allmersbach, Germany). The drum used for the laboratory scale machine had a single cavity for filling and cavity volume of $15 \mathrm{~mm}^{3}$ with target fill weight of $12.5 \mathrm{mg}$. The vacuum pressure for filling was set at 0.3 bar.

The reference formulation was collected from several commercial Flixotide ${ }^{\circledR}$ Accuhaler ${ }^{\circledR}$ products, which were also filled into the test inhaler cavities using the same OmniDose ${ }^{\circledR}$ TT laboratory scale drum filler.

\section{Blend Content Uniformity Analysis and High-Performance Liquid Chromatography Methodology}

The blend content uniformity analysis was based on 10 random samples. The amount of each sample was equal to one unit dose of the reference formulation (target $12.5 \mathrm{mg}$ ) and was weighed into a $50-\mathrm{mL}$ volumetric flask. Sample randomization was achieved by pouring the powder formulation onto a clean sheet of paper, dividing into 10 segments and sampling from each segment. Samples were dissolved in mobile phase and then made to volume $(50 \mathrm{~mL})$ before analysis. The pre-defined acceptance criterion for blend content uniformity was a relative standard deviation (RSD) of drug concentration less than $5 \%$ across the 10 random samples collected and analyzed for each formulation blend.

The drug content was detected and quantified using HPLC. The HPLC system consisted of a pump coupled to an auto-sampler and multi-wavelength UV detector (Agilent
1200, Wokingham, UK) set at a wavelength of $235 \mathrm{~nm}$. The pump flow rate was set to $1.5 \mathrm{~mL} / \mathrm{min}$ through a Hypersil ODS- $\mathrm{C}_{18}$ column (Fisher Scientific, Loughborough, UK, column length of $250 \mathrm{~mm}$, internal diameter of $4.6 \mathrm{~mm}$, and packing material particle size of $5 \mu \mathrm{m}$ ), which was placed in a column oven (Agilent, Wokingham, UK) set to $40^{\circ} \mathrm{C}$. The mobile phase consisted of methanol, acetonitrile and water (45:30:20\% $v / v)$ and the injection volume was set to $50 \mu \mathrm{L}$. The elution time for the drug peak was $3.4 \mathrm{~min}$. Linear regression analysis was used for the assessment of HPLC calibration. Quantification was carried out by an external standard method, and linearity was verified between 0.05 and $50 \mu \mathrm{g} / \mathrm{mL}\left(R^{2}=1.00\right)$. The API remained stable within the mobile phase system, and no drug degradation was observed during the measurements.

\section{Cascade Impaction Measurements}

In vitro characterization of aerosolization performance of test and reference DPI products for parts I and II of the study was performed using a Next Generation Impactor (NGI) with a pre-separator, which was connected to a vacuum pump (GE Motors, MI, USA). Prior to testing, the pre-separator was filled with $15 \mathrm{~mL}$ of mobile phase described above. The NGI cups were coated with $1 \% v / v$ silicone oil in hexane to eliminate particle bounce. For each experiment, three individual shots were discharged into the NGI using the reference or test device at $30 \pm 0.5,60 \pm 0.5$ and $90 \pm 1.8 \mathrm{~L} / \mathrm{min}$ for duration of time representative of an inhaled volume of $4 \mathrm{~L}$. Following aerosolization, the NGI apparatus was dismantled, and each part of the NGI was washed down using known volumes of mobile phase through multiple washings. The mass of drug deposited on each stage, mouthpiece, induction port and pre-separator, including the device, was determined by HPLC. This protocol was repeated in triplicate for the Accuhaler ${ }^{\circledR}$, MultiHaler ${ }^{\circledR}$, MOD MH 1 and MOD MH 2 with the reference and/or test DPI formulations.

The unmodified MultiHaler ${ }^{\circledR}$ device was not tested with Flixotide ${ }^{\circledR}$ Accuhaler ${ }^{\circledR}$ formulation, because access to the cartridges of the unmodified MultiHaler ${ }^{\circledR}$ device would have resulted in damage to the airflow path of the device, thereby impairing device performance.

The ED, impactor-sized mass (ISM), fine particle mass (FPM), mass median aerodynamic diameter (MMAD) and geometric standard deviation (GSD) were determined from the analysis of the NGI data. The ED was defined as the mass of drug collected on the inlet port, pre-separator and stages $1-8$, and the ISM was defined as the mass of drug collected on stages 2-8 of the NGI. FPM was defined as the mass of drug particles less than $5 \mu \mathrm{m}$. FPM, MMAD and GSD were calculated based upon the inverse normal of the cumulative $\%$ under the stated aerodynamic diameter versus log of the effective cut-off diameter. Linear regression of the five data points closest to $50 \%$ of the cumulative particle mass that entered the cascade impactor (CI) was performed to compute MMAD and GSD. The cut-off diameters were calculated and corrected for the three different flow rates utilized in the study according to USP <601> (24). In all CI tests conducted, the mass balance was within $\pm 15 \%$ of the total recovered dose. 


\section{RESULTS}

\section{Part I-Device Characterization}

\section{CFD Modelling}

CFD modelling geometries of the Accuhaler ${ }^{\circledR}$ and MultiHaler® are shown in Fig. $1 \mathrm{a}$ and b, respectively. The applicability of these CFD models to the device operation along with functionality of the key components is summarized below.

The Accuhaler ${ }^{\circledR}$ device consists of a sealed blister pocket, which is aligned with the mouthpiece. The patient operates the inhaler by sliding a lever, which increments the dose, simultaneously peels the two layers of foil apart and opens the mouthpiece. Upon patient's inspiratory effort, the powder dose fluidizes from the blister pocket and exits the device at the mouthpiece (Fig. 1a). The MultiHaler ${ }^{\circledR}$ device consists of 30 pre-metered doses, which are stored within cartridges that are covered by aluminium foil. The patient operates the inhaler by sliding the actuation slider, which lowers the lever arm over the cartridge. A perforation tube, attached to the lever arm, pierces the aluminium cover over the cartridge to gain access to the dose. Upon patient's inspiratory effort, the powder is drawn out of the cartridge through the perforation tube and lever arm (Fig. 1b) and evacuated at the mouthpiece.

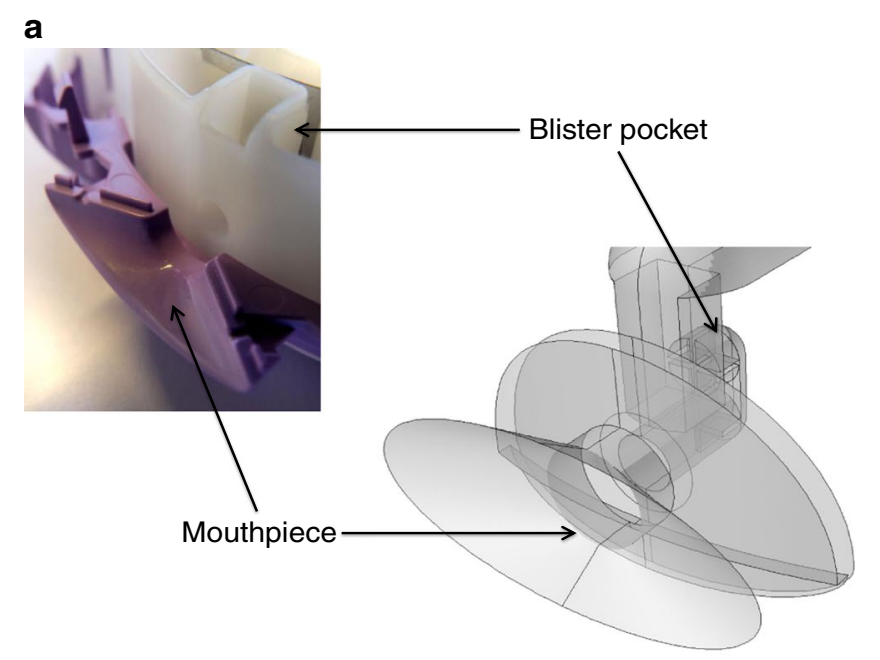

b

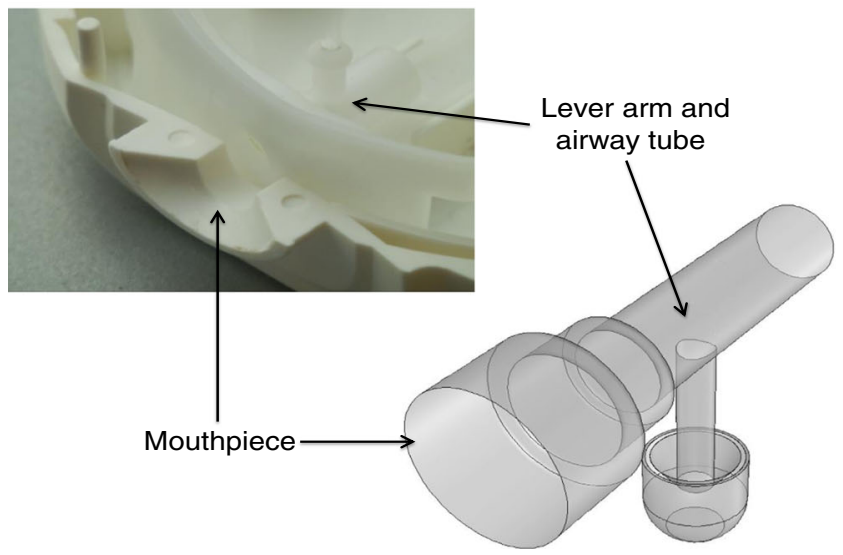

Fig. 1. CFD models of the $\mathbf{a}$ Accuhaler ${ }^{\circledR}$ and $\mathbf{b}$ unmodified MultiHaler ${ }^{\circledR}$
The pressure and velocity distribution as well as particle trajectories were computed for the Accuhaler $\AA$, MultiHaler $\AA$, MOD MH 1 and MOD MH 2 at 30, 60 and $90 \mathrm{~L} / \mathrm{min}$. A comparison of the pressure and velocity distribution for Accuhaler ${ }^{\circledR}$ and MultiHaler ${ }^{\circledR}$ indicates that the local pressure drop calculated across the MultiHaler ${ }^{\circledR}$ cartridge was greater than that simulated across the Accuhaler ${ }^{\circledR}$ blister pocket (Table I). In addition, Table I shows that the velocity of the airflow through the MultiHaler ${ }^{\circledR}$ cartridge $(60 \mathrm{~m} / \mathrm{s})$ was considerably higher than that through the Accuhaler® blister pocket $(30 \mathrm{~m} / \mathrm{s})$. The particle tracking profiles of $30-\mu \mathrm{m}$ particles in both DPI devices were also noticeably different as shown in Fig. 2. Specifically, the residence time of $30-\mu \mathrm{m}$ particles in the MultiHaler ${ }^{\circledR}$ was $30 \mathrm{~ms}$ (Fig. 2(B)), which was ten times greater than that in the Accuhaler® (Fig. 2(B')). Furthermore, the particles were found to impact the inner surfaces of the airway with significantly greater energy in the MultiHaler ${ }^{\circledR}$ compared to Accuhaler®. In CFD, the impact energy is characterized by the velocity with which the particles impact the airway surfaces, specifically the normal component of this impact velocity $V_{n}$. The average $V_{n}$ was found to be three times greater in the MultiHaler ${ }^{\circledR}$ than the Accuhaler ${ }^{\circledR}$.

Two modifications were investigated in the CFD simulations with the aim of providing a better matching to the Accuhaler® with respect to the aerosolization performance. These two modifications, MOD MH 1 and MOD MH 2, were modelled by introducing one and two $0.2-\mathrm{mm}$ by-pass channels, respectively, between the lever arm and mouthpiece of the MultiHaler ${ }^{\circledR}$ (Fig. 1b). The local pressure drop and velocity data for MOD MH 1 and MOD MH 2 are summarized in Table I. The introduction of one by-pass channel in MOD MH 1 resulted in reduction of the local pressure drop and the velocity of the airflow through the cartridge by 50 and $25 \%$, respectively. However, this local pressure drop and airflow velocity of MOD MH 1 was still higher than that observed for Accuhaler®. In comparison, by introduction of additional (a total of two) by-pass channels in MOD MH 2, the local pressure drop and airflow velocity in this modified device were further reduced and became comparable to that observed for Accuhaler®.

\section{In Vitro Characterization}

Figure 3 shows the relationship between device pressure drop and flow rate for the Accuhaler ${ }^{\circledR}$, MultiHaler ${ }^{\circledR}$, MOD MH 1 and MOD MH 2. The specific resistances of these four

Table I. Pressure Drop Across the Complete Device and Across the Blister Component $(\mathrm{Pa})$, and Airflow Velocity Within the Blister $(\mathrm{m} / \mathrm{s})$ in the Accuhaler ${ }^{\circledR}$, MultiHaler ${ }^{\circledR}$ and Modified MultiHaler ${ }^{\circledR}$ Devices (MOD MH 1 and MOD MH 2). Blister Pressure Drop and Airflow Velocity Were Determined Through CFD Simulations

\begin{tabular}{lccc}
\hline Device & $\begin{array}{c}\text { Total device } \\
\text { pressure drop }(\mathrm{Pa})\end{array}$ & $\begin{array}{c}\text { Blister pressure } \\
\text { drop }(\mathrm{Pa})\end{array}$ & $\begin{array}{c}\text { Velocity } \\
(\mathrm{m} / \mathrm{s})\end{array}$ \\
\hline Accuhaler ${ }^{\circledR}$ & 4000 & 700 & 30 \\
MultiHaler ${ }^{\circledR}$ & 4000 & 2500 & 60 \\
MOD MH 1 & 4000 & 1200 & 40 \\
MOD MH 2 & 4000 & 700 & 30 \\
\hline
\end{tabular}



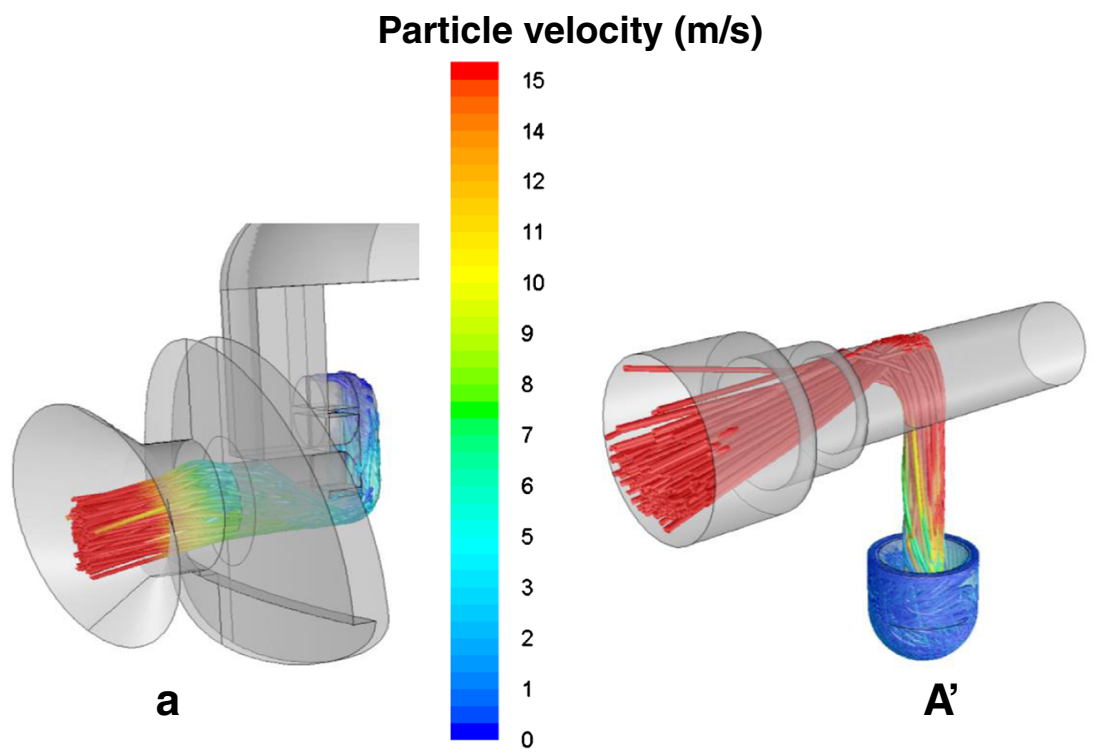

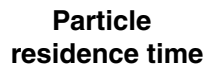

(s)

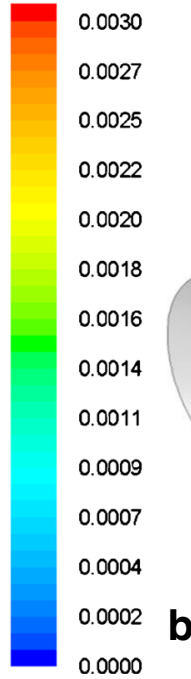

\section{Particle}

residence time

(s)

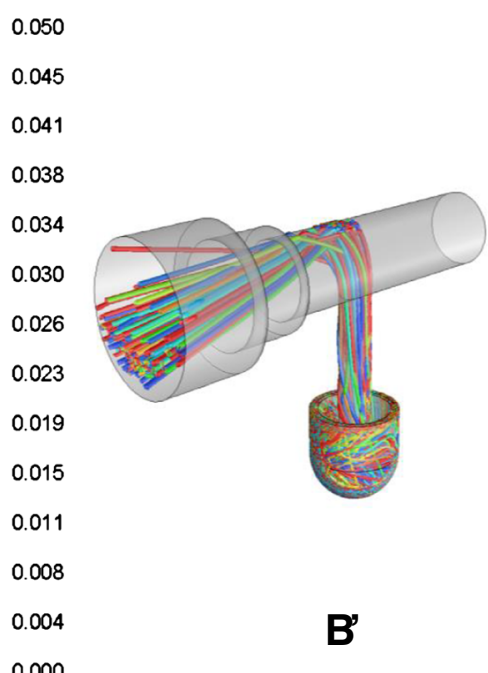

Fig. 2. Particle impaction velocity in $A$ Accuhaler ${ }^{\circledR}$ and $A^{\prime}$ unmodified MultiHaler ${ }^{\circledR}$ at $60 \mathrm{~L} / \mathrm{min}$. Particle tracks coloured by particle residence time for $B$ Accuhaler ${ }^{\circledR}$ and $B^{\prime}$ unmodified MultiHaler ${ }^{\circledR}$. Particle simulation is of $30 \mu \mathrm{m}$ in both devices

DPI devices were comparable. For example, the difference in the specific resistance between the Accuhaler ${ }^{\circledR}$ and MOD MH 2 [i.e. 0.0256 and $0.0254(\mathrm{KPa})^{1 / 2} \mathrm{~L}^{-1} \mathrm{~min}$, respectively] was less than $1.0 \%$.

The in vitro aerosolization performance of the Accuhaler®, MOD MH 1 and MOD MH 2 was characterized by using the reference formulation that was extracted from Flixotide ${ }^{\circledR}$ Accuhaler ${ }^{\circledR}$. The ED, ISM, FPM, MMAD and GSD of the three DPIs, based on the reference formulation, at three flow rates of 30,60 and $90 \mathrm{~L} / \mathrm{min}$ are summarized in Table II, and the respective full CI profile at 30, 60 and $90 \mathrm{~L} / \mathrm{min}$ is provided as supplemental materials (Fig. S1). These CI data indicate that at all three flow rate modifications made to the MultiHaler ${ }^{\circledR}$ provided improved comparability in its aerosolization performance to the Accuhaler ${ }^{\circledR}$, with MOD
MH 2 providing best matching to the Accuhaler® among all three test DPI devices.

\section{Part II-Formulation Preparation and Characterization}

\section{Material Characterization of Fluticasone Propionate} and Lactose Monohydrate

All four FP batches selected for this study contained drug particles with $d_{10}, d_{50}$ and $d_{90}$ ranging from $0.96-1.20$, $2.00-2.73$ to $5.17-7.41 \mu \mathrm{m}$, respectively. In addition, the specific surface area of the four FP batches ranged from 6.54 to $7.95 \mathrm{~m}^{2} / \mathrm{g}$. These physicochemical properties are summarized in Table III. Furthermore, the SEMs (Fig. S2) suggested that FP particles in the four FP batches exhibited 


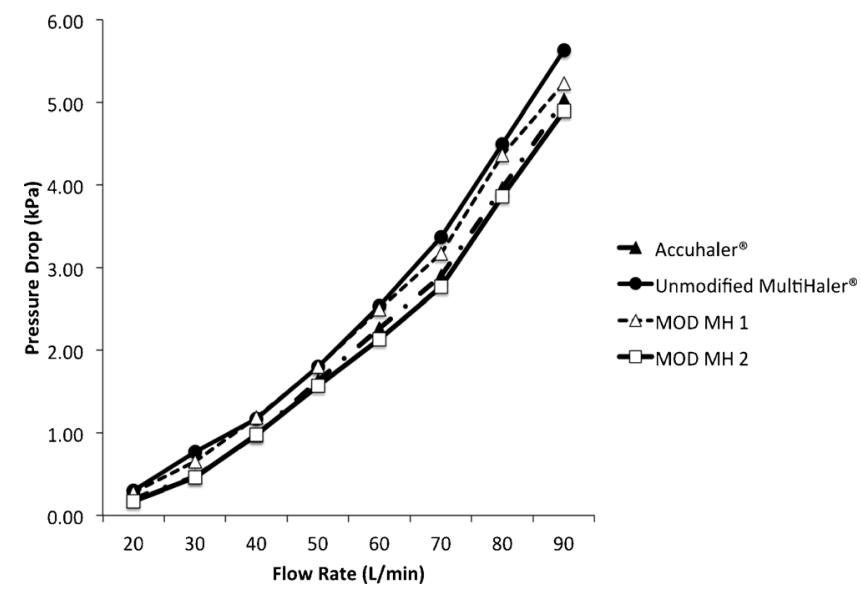

Fig. 3. The relationships between the pressure drop and flow rate for Accuhaler ${ }^{\circledR}$, unmodified MultiHaler ${ }^{\circledR}$, MOD MH 1 and MOD MH 2

irregular morphology, with evidence of particle agglomeration possibly due to the cohesive nature of the API. Table IV shows the PSD, characterized by the $d_{10}, d_{50}, d_{90}$ and fine content ( $\%$ $<5 \mu \mathrm{m}$ ) of milled (ML001) and sieved lactose (SV003). Although the PSD data for ML001 suggested that it possessed a significantly greater amount of fine lactose particles than the SV003, the $d_{90}$ of ML001 was greater than that of SV003.

CAB plots for the four FP batches (Fig. S3), which were generated by plotting the mean force of cohesion (interactions between the drug probe and drug crystal) of five probes against the corresponding mean force of adhesion (interactions between the drug probe and lactose crystal), showed a linear fit with a regression coefficient ranging from 95.5 to $99.7 \%$. The CAB ratio of batch A FP was $0.94 \pm 0.01$, which suggested that batch A FP had similar cohesive FP-FP and adhesive FP-lactose forces. The $\mathrm{CAB}$ ratio of batches $\mathrm{B}$ and C FP was $0.82 \pm 0.02$ and $0.65 \pm 0.02$, respectively, which suggested that the adhesive interactions of these FP batches to lactose were 1.22 and 1.54 times greater than their cohesive FP-FP interactions. However, the adhesive interaction of batch D FP was approximately 2.4 times greater than the cohesive FP-FP interactions. These data indicate that the surface interfacial properties of all four batches of FP were different, with batch D FP exhibiting the greatest and batch A the least adhesion to lactose.

\section{Blend Content Uniformity and Cascade Impaction Analysis of Test Formulations}

The RSD for drug content of binary formulations of batches A-D for FP with ML001 and SV003 were all less than $5 \%$, suggesting uniform blending of the DPI formulation (Table V). Furthermore, the USP <905> acceptance value of these batches was less than 15 , which confirmed that they met the acceptance criteria of USP $<905>$. Tables VI and VII also show the ED, ISM, FPM, MMAD and GSD for FP batches A-D with SV003 and ML001, aerosolized from MOD MH 2 at 30, 60 and $90 \mathrm{~L} / \mathrm{min}$, respectively. Their respective full CI profiles at 30,60 and $90 \mathrm{~L} / \mathrm{min}$ are provided as supplemental materials in Fig. S4 A-C and S5 A-C, respectively.

The EDs of the four test formulations produced using SV003 at the three flow rates of 30,60 and $90 \mathrm{~L} / \mathrm{min}$ ranged

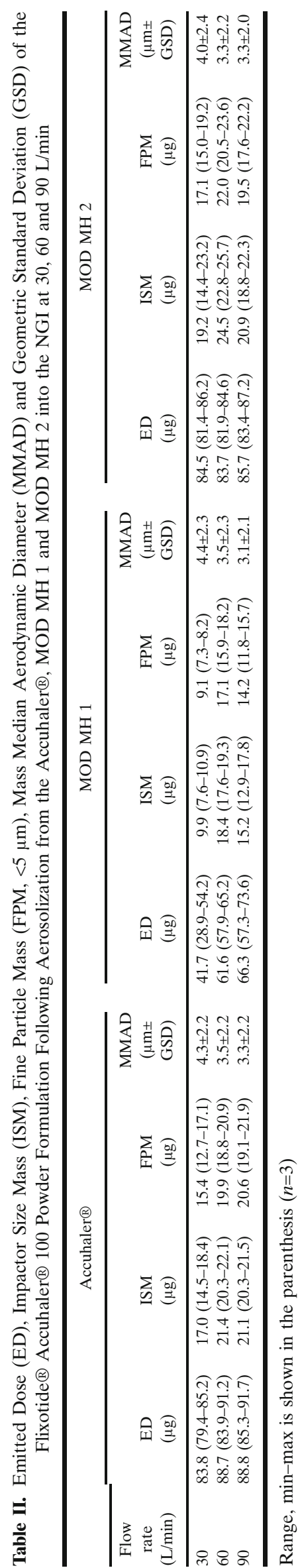


Table III. Particle Size Distribution, Specific Surface Area and CAB Ratio of Four Different Batches of Micronized Fluticasone Propionate (FP)

\begin{tabular}{|c|c|c|c|c|c|}
\hline \multirow[b]{2}{*}{ FP batches } & \multicolumn{3}{|c|}{ Particle size distribution $(\mu \mathrm{m})$} & \multirow[b]{2}{*}{ Specific surface area $\left(\mathrm{m}^{2} / \mathrm{g}\right)$} & \multirow[b]{2}{*}{ CAB ratio } \\
\hline & $d_{10}$ & $d_{50}$ & $d_{90}$ & & \\
\hline A & $1.20(1.15-1.26)$ & $2.00(1.94-2.04)$ & $5.72(5.70-5.74)$ & $7.95(7.88-8.04)$ & $0.94(0.93-0.95)$ \\
\hline B & $1.20(1.18-1.22)$ & $2.72(2.70-2.74)$ & $5.17(5.15-5.19)$ & $6.85(6.78-6.89)$ & $0.82(0.81-0.83)$ \\
\hline $\mathrm{C}$ & $0.96(0.94-0.98)$ & $2.65(2.60-2.72)$ & $7.41(7.38-7.43)$ & $7.76(7.64-7.79)$ & $0.65(0.63-0.66)$ \\
\hline $\mathrm{D}$ & $0.98(0.95-0.99)$ & $2.73(2.68-2.74)$ & $5.25(5.19-5.27)$ & $6.54(6.51-6.56)$ & $0.42(0.41-0.43)$ \\
\hline
\end{tabular}

Range, min-max is shown in the parenthesis $(n=3)$

from 80 to $91 \mu \mathrm{g}$. For batch A FP formulated with SV003 (SV A), the mean MMAD decreased by $12 \%$ (i.e. 3.2 to $2.6 \mu \mathrm{m}$ ) as the flow rate increased from 30 to $90 \mathrm{~L} / \mathrm{min}$, indicating that more fine particles were generated at higher flow rates. In contrast, for FP batches B and D formulated with SV003 (SV B and SV D), the mean MMAD remained between 2.8 and $3.1 \mu \mathrm{m}$ and 2.7 and $2.9 \mu \mathrm{m}$, respectively. The mean MMAD of batch $\mathrm{C}$ formulated with SV003 (SV C) was $2.9 \mu \mathrm{m}$ at 30 and $90 \mathrm{~L} / \mathrm{min}$, but decreased to $2.5 \mu \mathrm{m}$ at $60 \mathrm{~L} / \mathrm{min}$. The FPM of all four formulations increased as the flow rate increased. There was no difference between the stage deposition profiles within the ISM of the four SV003 formulations at a flow rate of $30 \mathrm{~L} / \mathrm{min}$. However, the SV003 formulations containing batches C and D FP had 12 and $42 \%$ higher pre-separator deposition as compared to those containing batches A and B FP at flow rates of 60 and $90 \mathrm{~L} / \mathrm{min}$, respectively. Consequently, batches $\mathrm{A}$ and $\mathrm{B}$ had the highest ISM among all formulations produced with SV003.

The EDs for the four test formulations produced using ML001 at each of the three flow rates tested are similar to those produced using SV003 and ranged from 81 to $99 \mu \mathrm{g}$. For all of the four ML001 formulations, the mean MMAD decreased by $32 \%$ (i.e. 3.9 to $2.9 \mu \mathrm{m}$ ) as the flow rate increased from 30 to $90 \mathrm{~L} / \mathrm{min}$. Similar to the SV003 formulations, the ML001 formulations containing batches A and B FP had higher preseparator deposition as compared to those containing batches $\mathrm{C}$ and D FP at $60 \mathrm{~L} / \mathrm{min}$. Consequently, batches $\mathrm{C}$ and D had the highest ISM among all formulations produced with ML001. For the same flow rates, the ISMs for the ML001 formulations are approximately two times greater than the SV003 formulations.

The EDs for FP formulations produced using SV003 and ML001 and aerosolized using MOD MH 2 are similar to those of the Flixotide ${ }^{\circledR}$ Accuhaler ${ }^{\circledR}(83-89 \mu \mathrm{g})$. However, FP formulations produced using SV003 had higher pre-separator deposition than ML001 FP formulations and Flixotide ${ }^{\circ}$ Accuhaler ${ }^{\circledR}$. As a result, the ISM of FP formulations produced using ML001 are two times greater than that for SV003 FP formulations and Flixotide ${ }^{\circledR}$ Accuhaler ${ }^{\circledR}$ at all three flow rates.

\section{DISCUSSION}

The critical components of a passive DPI device include the dosing system, internal geometry and materials used for construction. These components have a direct influence on the device resistance and primary mechanisms of fluidization and de-aggregation of aerosol particles. Hence, significant differences in the airflow resistance and airflow path of the test and reference DPIs may preclude in vitro equivalence of test and reference products.

Accuhaler ${ }^{\circledR}$ and unmodified MultiHaler ${ }^{\circledR}$, which had similar specific resistance, demonstrated such noticeable differences in their airflow pathways. As indicated in the CFD analysis, the Accuhaler ${ }^{\circledR}$ airflow path resulted in the powder dose to be fluidized from the blister pocket and transported to the mouthpiece, with short particle residence time. These data suggest that once the particles are entrained into the airflow, there are no significant impaction events during transit of the powder dose from the blister pocket to the mouthpiece (particle impact velocity $<5 \mathrm{~m} / \mathrm{s}$ ). The local pressure drop across the blister pocket was $700 \mathrm{~Pa}$ determined at $60 \mathrm{~L} / \mathrm{min}$. Tuley et al. have reported powder fluidization and entrainment of powder doses within a cavity once a critical pressure drop across the cavity was reached (25). Therefore, this local pressure drop across the blister pocket of the Accuhaler ${ }^{\circledR}$ device may aid powder fluidization, entrainment and particle re-suspension.

In contrast, CFD analysis suggested that the impact velocity of particles in MultiHaler® air-path was three times greater than that measured in Accuhaler ${ }^{\circledR}$ air-path. This is primarily related to the arrangement of the airflow path within the MultiHaler ${ }^{\circledR}$. Once entrained in the MultiHaler ${ }^{\circledR}$ air-path, the particles accelerate up the perforation tube, resulting in their impact directly into the lever arm wall. The generation of these high impact velocity events is likely to correspond with deposition and/or de-aggregation of drug particles. Hence, whilst the specific resistance of Accuhaler ${ }^{\circledR}$ and MultiHaler ${ }^{\circledR}$ are similar, the entrained particles in

Table IV. Particle Size Distribution and Powder Rheological Measurements of Milled (ML001) and Sieved (SV003) Lactose

\begin{tabular}{llll} 
& & \multicolumn{2}{c}{ Particle size distribution $(\mu \mathrm{m})$} \\
\cline { 2 - 4 } Batch & \multicolumn{1}{c}{$d_{10}$} & \multicolumn{1}{c}{$d_{50}$} & $d_{90}$ \\
\hline ML001 & $2.77(2.76-2.78)$ & $33.32(33.28-33.34)$ & $148.07(147.89-148.15)$ \\
SV003 & $15.51(15.48-15.53)$ & $56.80(56.32-56.84)$ & $92.59(90.39-93.43)$ \\
\hline
\end{tabular}

Range, min-max is shown in the parenthesis $(n=3)$ 
Table V. Blend Content Uniformity (BCU) of Test Formulations Containing Batches A, B, C and D FP Formulated with Milled (ML) and Sieved (SV) Lactose Expressed as Percentage Relative Standard Deviation (\%RSD) and USP $<905>$ Acceptance Value (AV)

\begin{tabular}{lccc}
\hline Blend & \% mean assay & \%RSD & USP $<905>$ AV \\
\hline ML A & 98.7 & 4.1 & 8.3 \\
ML B & 99.1 & 3.5 & 6.7 \\
ML C & 99.8 & 3.2 & 4.5 \\
ML D & 104.5 & 2.1 & 6.2 \\
SV A & 99.2 & 4.3 & 10.3 \\
SV B & 99.0 & 3.9 & 9.2 \\
SV C & 100.1 & 2.8 & 3.9 \\
SV D & 98.5 & 1.9 & 5.1 \\
\hline
\end{tabular}

MultiHaler ${ }^{\circledR}$ may impact on walls of the lever arm of the device, which may influence the device performance. Based on our previous work, the greater velocity of impaction events in the MultiHaler $\AA$, resulting from differences in airflow path of the two devices, is likely to preclude comparable in vitro aerosolization performance with respect to the Accuhaler® (10).

One of the possible approaches to modify the air-path of MultiHaler $\AA$, to be similar to that of Accuhaler ${ }^{\circledR}$, was to reduce the efficiency of the device by introducing additional by-pass air channels. The presence of the by-pass air channels would allow additional airflow to enter the device air-path, resulting in reduction of local pressure drop and velocity at the cartridge and velocity of the entrained particles. Therefore, as a step towards achieving comparative device performance of the two devices, modifications were made to the MultiHaler ${ }^{\circledR}$ to include $0.2-\mathrm{mm}$ by-pass air channel inlets between the lever arm and the mouthpiece. In this way, two modified MultiHaler ${ }^{\circledR}$ devices were manufactured, which contained only one by-pass channel (MOD MH 1) or two by-pass channels (MOD MH 2). The in vitro aerosolization performance of MOD MH 1 and $\mathrm{MH} 2$ with respect to Accuhaler ${ }^{\circledR}$, using the reference product formulation, suggested that the ED and ISM of MOD MH 1 was lower than that of Accuhaler ${ }^{\circledR}$ at all flow rates tested. This may be related to greater retention of drug in the MultiHaler ${ }^{\circledR}$ device due to impaction of the drug into the lever arm. In addition, the performance of MOD MH 1, as measured by percentage fine particle fraction of the emitted dose $(30 \%$ at $60 \mathrm{~L} / \mathrm{min})$, was greater than that of Accuhaler® and MOD MH 2. Therefore, these data suggested that MOD MH 1 was not a suitable test device. In contrast, the ED and ISM of MOD MH 2 were comparable to the Accuhaler ${ }^{\circledR}$. Moreover, MOD MH 2 provided greater comparability of the stage-by-stage deposition to Accuhaler ${ }^{\circledR}$ at all flow rates tested. These data suggest that modification of MultiHaler®, by introduction of two by-pass air channels, was successful in producing an airpath that was comparable to Accuhaler ${ }^{\circledR}$, resulting in comparable in vitro aerosolization performance. Hence, MOD MH 2 was selected as the test device in reference to Accuhaler®.

The effect of by-pass channels on the performance of MOD MH 1 and MOD MH 2, in comparison to MultiHaler ${ }^{\circledR}$, emphasizes the importance of controlling the machining and tooling of these complex products. Injection moulded parts
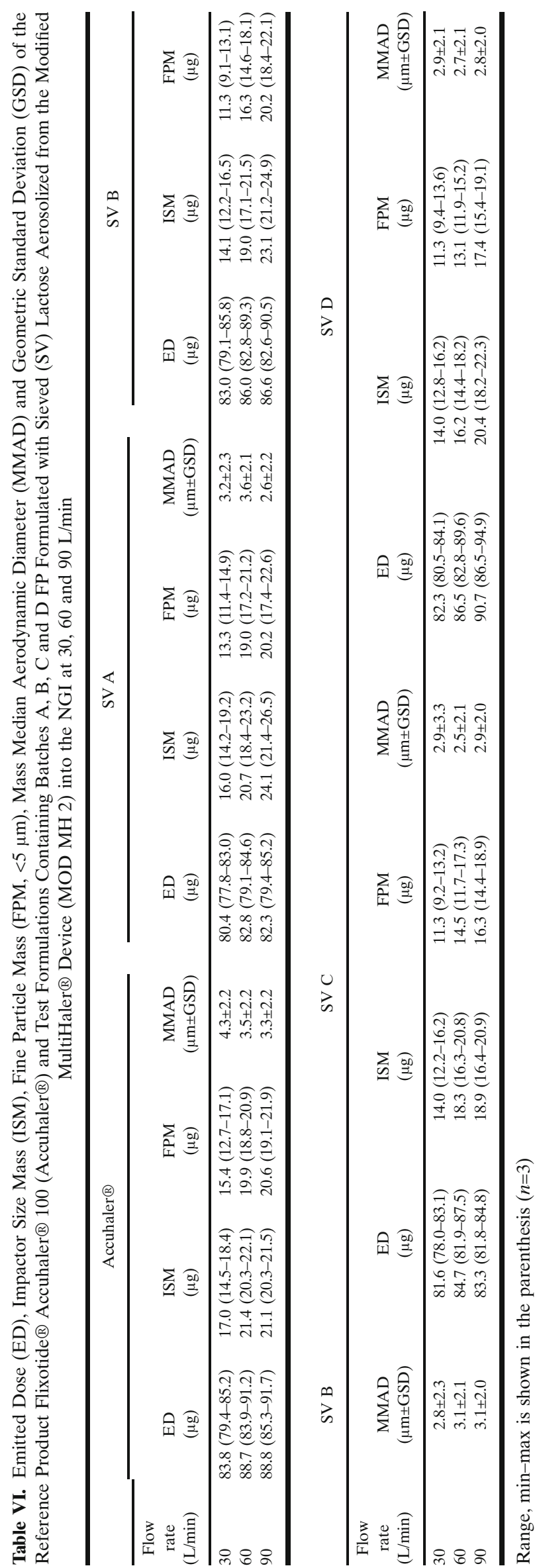


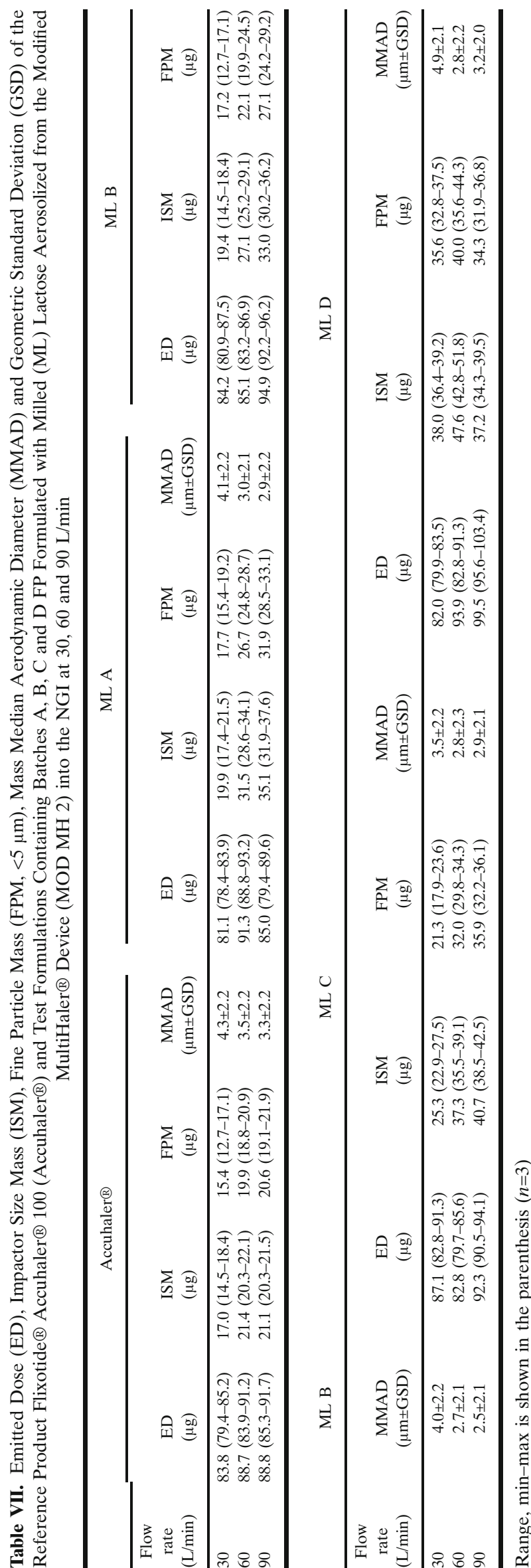

are prone to suffer from shrinkage, which results in imperfections in the device airflow path that may affect entrained particles and thereby drug product performance (26). Hence, this may be an important element to inspect and control from a product development and manufacturing perspective, since small differences may have a significant bearing on interdevice variability.

Another key challenge to producing a bioequivalent test DPI drug product is the manufacture of a powder formulation with functionality to enable comparable in vitro performance of the test device to the reference device. Although described as simple blends of micronized API and lactose, performance of DPI formulations is dependent on the physicochemical properties of the raw materials and their surface interfacial interactions. These interfacial forces govern the overall relationship between device and de-aggregation efficiency and, therefore, directly influence the in vitro deposition profile of the drug product (9).

For DPI formulation systems, particle size of both API and lactose are critical quality attributes that must be defined and specified. In the present study, particle size evaluation of the reference product (Flixotide ${ }^{\circledR}$ Accuhaler ${ }^{\circledR}$ ) enabled the specification of a desired particle size for FP. These specifications were used to source four batches of FP from different vendors, with the aim of achieving the target MMAD $(3.4 \mu \mathrm{m})$ and GSD (2.4) based the CI analysis of Flixotide ${ }^{\circledR}$ Accuhaler ${ }^{\circledR}$ at 60 LPM. Numerous studies have shown that carrier lactose containing intrinsic or extrinsic fine excipient material can dramatically affect the performance of DPI formulations $(27,28)$. The mechanisms by which fines improve DPI formulation performance remain speculative; the "active site" and "drug/fines agglomerate" theories have been proposed (7). In order to investigate the impact of fines and particle size of lactose on the aerosolization performance of different batches of API, milled (ML001) and sieved (SV003) lactose carrier materials were selected. Typically, the milled lactose material had more intrinsic fines than the sieved lactose material.

Investigation of the material properties of the different API batches suggested variations in their particle size and surface interfacial properties as measured by CAB. These data highlight the challenges faced during generic drug product development, particularly as in most cases, the API and excipient are procured through third-party channels. Our previous work has suggested that variation in particle size and interfacial properties may be related to the process history of the API (23). In particular, the elastic properties of primary FP crystals that are secondarily processed by air-jet micronization results in material that does not always meet particle size specification and has variable surface interfacial properties. This has been shown to impact finished drug product performance in both binary and combination DPI formulations (23). In order to understand the impact of the surface interfacial forces of the API on in vitro drug deposition, all batches of API were formulated with either milled or sieved lactose for further formulation investigation with the MOD MH 2 test device.

Both batches A and D FP showed differences in formulation performance when formulated with ML001 and SV003 lactose monohydrate. In comparison to the sieved formulations of both APIs, the in vitro stage-by-stage deposition for both batches of FP was greater when formulated with milled 
lactose. This is primarily related to the greater fine excipient $(<5 \mu \mathrm{m})$ content of ML001 in comparison to SV003. CAB analysis of the two FP batches suggested that batch D FP had a greater adhesion to lactose carrier than batch A FP. As a result, the in vitro $\mathrm{CI}$ deposition of batch $\mathrm{D}$ FP formulated with sieved lactose was lower than batch A FP when formulated with the same lactose. These data suggest that greater adhesion of batch $\mathrm{D}$ FP to lactose limited the de-aggregation of drug particles from the carrier, thereby lowering the emission of fines that enter the CI. Such trends have been previously reported by Hooton et al. and Jones et al. (16,17). Conversely, however, the stage-by-stage deposition and ISM of batch D FP, when formulated with ML001, was greater than that of batch A FP/ML001 formulations. Previously, Jones et al. had reported that the aerosolization performance of APIs with $\mathrm{CAB}$ ratio less than 1 (i.e. adhesive to the carrier) is greater than APIs with CAB ratios greater than 1 , when formulated with carrier material with high fine excipient content (28). They postulated that this might be related to the formation of drug/excipient fine agglomerates that are aerosolized more efficiently. In the present study, it is likely that batch D FP when formulated with ML001 forms such agglomerated systems that aids aerosolization performance. Indeed, evidence of such agglomerate formation of batch D FP is shown in Table VII, which shows that MMAD of this formulation was large (approx. $5 \mu \mathrm{m}$ ). The performance of the milled lactose formulations resulted in higher CI deposition of the API. The aerosolization of agglomerates and the impaction of the particles on walls of the lever arm in MOD MH 2 may aid further particle re-suspension and, therefore, greater release of fine API material. Batch A FP formulated with sieved lactose demonstrated the highest degree of similarity to Accuhaler® in the CI measurements.

The present study highlights that percent fines $($ i.e. $<5 \mu \mathrm{m})$ of lactose carrier can dramatically affect the aerosolization performance of DPI formulations. In contrast, however, the effect of the API particle size on in vitro aerosolization performance was not so obvious. In DPI formulation systems, API surface interfacial properties are known to affect drug product performance $(13,17,29,30)$. Traditionally, the surface interfacial properties of APIs have been measured indirectly through measurement of amorphous content or surface free energy (31,32). Although important, these data do not provide direct information regarding the interfacial force balance within the DPI formulation system. The AFM-CAB measurement tool enables direct measurement of the surface interfacial force balance, which can be used to support formulation strategies through selection of different grades of lactose to manipulate the stage-by-stage deposition behaviour of a product. The utility of this approach allows control of drug product performance to achieve in vitro comparability to reference products.

These data highlight the subtle nature of surface interfacial free energy of the DPI formulation components, which, in turn, may affect the performance of the final drug product (33). Hence, it is essential to understand the relationship between material processing and its influence on the physicochemical properties to formulate DPI drug products with desired performance characteristics.

\section{CONCLUSIONS}

The present study shows that in vitro comparability can be achieved for two apparently different multi-unit dose test and reference DPI devices, MultiHaler ${ }^{\circledR}$ and Accuhaler ${ }^{\circledR}$, respectively, through appropriate modifications of key attributes of the test DPI device. CFD modelling and in vitro characterization by a multi-stage cascade impactor were utilized to provide engineering assistance in identifying and understanding the key performance attributes, which would influence the criteria for designing and modifying a test DPI device. Similarly, the material property attributes of micronized fluticasone propionate and carrier lactose were measured to rationalize formulation selection to achieve comparable in vitro performance of test and reference product at three flow rates. This investigation illustrates the importance of enhanced device and formulation understanding, to enable fabrication and refinement of the test DPI device, and selection of formulation components, respectively, to provide a closer match to the aerosolization performance of the reference DPI device at multiple flow rates.

\section{REFERENCES}

1. Chrystyn H. The Diskus: a review of its position among dry powder inhaler devices. Int J Clin Pract. 2007;61:1022-36.

2. Coates MS, Chan H-K, Fletcher DF, Raper JA. Effect of design on the performance of a dry powder inhaler using computational fluid dynamics. Part 2: air inlet size. J Pharm Sci. 2006;95:1382-92.

3. Byron PR, Hindle M, Lange CF, Longest PW, McRobbie D, Oldham MJ, et al. In vivo-in vitro correlations: predicting pulmonary drug deposition from pharmaceutical aerosols. J Aerosol Med Pulm Drug Deliv. 2010;23 Suppl 2:S59-69.

4. Telko MJ, Hickey AJ. Dry powder inhaler formulation. Respir Care. 2005;50:1209-27.

5. Newman SP, Busse WW. Evolution of dry powder inhaler design, formulation, and performance. Respir Med. 2002;96:293-304.

6. Xu Z, Mansour HM, Mulder T, McLean R, Langridge J, Hickey AJ. Dry powder aerosols generated by standardized entrainment tubes from drug blends with lactose monohydrate: 2 . Ipratropium bromide monohydrate and fluticasone propionate. J Pharm Sci. 2010;99:3415-29.

7. Shur J, Harris H, Jones MD, Kaerger JS, Price R. The role of fines in the modification of the fluidization and dispersion mechanism within dry powder inhaler formulations. Pharm Res. 2008;25:1631-40.

8. Shur J, Lee S, Adams W, Lionberger R, Tibbatts J, Price R. Effect of device design on the in vitro performance and comparability for capsule-based dry powder inhalers. AAPS J. 2012;14:667-76.

9. Young PM, Tobyn MJ, Price R, Buttrum M, Dey F. The use of colloid probe microscopy to predict aerosolization performance in dry powder inhalers: AFM and in vitro correlation. J Pharm Sci [Internet]. 2006;95:1800-9.

10. Hickey AJ, Mansour HM, Telko MJ, Xu Z, Smyth HDC, Mulder $\mathrm{T}$, et al. Physical characterization of component particles included in dry powder inhalers. I. Strategy review and static characteristics. J Pharm Sci. 2007;96:1282-301.

11. Islam N, Stewart P, Larson I, Hartley P. Surface roughness contribution to the adhesion force distribution of salmeterol xinafoate on lactose carriers by atomic force microscopy. J Pharm Sci. 2005;94:1500-11.

12. Adi H, Traini D, Chan H-K, Young PM. The influence of drug morphology on aerosolisation efficiency of dry powder inhaler formulations. J Pharm Sci. 2008;97:2780-8.

13. Begat P, Morton DAV, Staniforth JN, Price R. The cohesiveadhesive balances in dry powder inhaler formulations II: influence on fine particle delivery characteristics. Pharm Res. 2004;21:1826-33.

14. Adams WP, Lee SL, Plourde R, Lionberger RA, Bertha CM, Doub WH, et al. Effects of device and formulation on 
in vitro performance of dry powder inhalers. AAPS J. 2012;14:400-9.

15. Begat P, Morton DAV, Staniforth JN, Price R. The cohesiveadhesive balances in dry powder inhaler formulations I: direct quantification by atomic force microscopy. Pharm Res. 2004;21:1591-7.

16. Hooton JC, Jones MD, Price R. Predicting the behavior of novel sugar carriers for dry powder inhaler formulations via the use of a cohesive-adhesive force balance approach. J Pharm Sci. 2006;95:1288-97.

17. Jones MD, Harris H, Hooton JC, Shur J, King GS, Mathoulin $\mathrm{CA}$, et al. An investigation into the relationship between carrierbased dry powder inhalation performance and formulation cohesive-adhesive force balances. Eur J Pharm Biopharm. 2008;69:496-507.

18. Lee SL, Adams WP, Li BV, Conner DP, Chowdhury BA, Yu LX. In vitro considerations to support bioequivalence of locally acting drugs in dry powder inhalers for lung diseases. AAPS J. 2009;11:414-23.

19. Shih TH, Liou WW, Shabbir A, Yang Z, Zhu J. A new k- $\epsilon$ eddy viscosity model for high reynolds number turbulent flows. Comput Fluids. 1995;24:227-38.

20. Launder BE, Rodi W. The turbulent wall jet measurements and modeling. Annu Rev Fluid Mech. 1983;15:429-59.

21. ANSYS. ANSYS Fluent 6.3 Users Guide. Lebanon, NH, USA. 2006. Available from: http://hpce.iitm.ac.in/website/Manuals/ Fluent_6.3/Fluent.Inc/fluent6.3/help/index.htm. Accessed 4 Nov 2010.

22. Stevens N, Shrimpton J, Palmer M, Prime D, Johal B. Accuracy assessments for laser diffraction measurements of pharmaceutical lactose. Meas Sci Technol. 2007;18:3697-706.

23. Kubavat HA, Shur J, Ruecroft G, Hipkiss D, Price R. Investigation into the influence of primary crystallization conditions on the mechanical properties and secondary processing behaviour of fluticasone propionate for carrier based dry powder inhaler formulations. Pharm Res. 2012;29:994-1006.

24. US Pharmacopeia. <601> Aerosols. Metered-dose inhalers and dry powder inhalers: particle size. Rockville: US Pharmacopeia 35/National Formulary 30, United States Pharmacopeial Convention; 2012.

25. Tuley R, Shrimpton J, Jones MD, Price R, Palmer M, Prime D. Experimental observations of dry powder inhaler dose fluidisation. Int J Pharm. 2008;358:238-47.

26. Postawa P, Koszkul J. Change in injection moulded parts shrinkage and weight as a function of processing conditions. J Mater Process Technol. 2005;162-163:109-15.

27. Young PM, Wood O, Ooi J, Traini D. The influence of drug loading on formulation structure and aerosol performance in carrier based dry powder inhalers. Int J Pharm. 2011;416:129-35.

28. Lucas P, Anderson K, Staniforth JN. Protein deposition from dry powder inhalers: fine particle multiplets as performance modifiers. Pharm Res. 1998;15:562-9.

29. Cline D, Dalby R. Predicting the quality of powders for inhalation from surface energy and area. Pharm Res. 2002;19:1274-7.

30. Chikhalia V, Forbes RT, Storey RA, Ticehurst M. The effect of crystal morphology and mill type on milling induced crystal disorder. Eur J Pharm Sci. 2006;27:19-26.

31. Gaisford S, Dennison M, Tawfik M, Jones MD. Following mechanical activation of salbutamol sulphate during ball-milling with isothermal calorimetry. Int J Pharm. 2010;393:74-8.

32. Planinsek O, Buckton G. Inverse gas chromatography: considerations about appropriate use for amorphous and crystalline powders. J Pharm Sci. 2003;92:1286-94.

33. Kubavat HA, Shur J, Ruecroft G, Hipkiss D, Price R. Influence of primary crystallisation conditions on the mechanical and interfacial properties of micronised budesonide for dry powder inhalation. Int J Pharm. 2012;430:26-33. 